\title{
Influence of the Arctic Oscillation on the vertical distribution of clouds as observed by the A-Train constellation of satellites
}

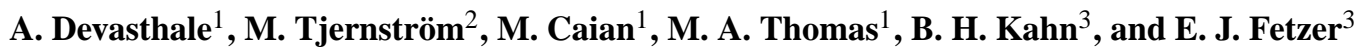 \\ ${ }^{1}$ Swedish Meteorological and Hydrological Institute (SMHI), Norrköping, Sweden \\ ${ }^{2}$ Department of Meteorology (MISU) and Bert Bolin Center for Climate Research, Stockholm University, Stockholm, Sweden \\ ${ }^{3}$ Jet Propulsion Laboratory/CALTECH, NASA, Pasadena, USA
}

Correspondence to: A. Devasthale (abhay.devasthale@smhi.se)

Received: 26 March 2012 - Published in Atmos. Chem. Phys. Discuss.: 20 April 2012

Revised: 22 October 2012 - Accepted: 1 November 2012 - Published: 12 November 2012

\begin{abstract}
The main purpose of this study is to investigate the influence of the Arctic Oscillation (AO), the dominant mode of natural variability over the northerly high latitudes, on the spatial (horizontal and vertical) distribution of clouds in the Arctic. To that end, we use a suite of sensors onboard NASA's A-Train satellites that provide accurate observations of the distribution of clouds along with information on atmospheric thermodynamics. Data from three independent sensors are used (AQUA-AIRS, CALIOP-CALIPSO and CPR-CloudSat) covering two time periods (winter half years, November through March, of 2002-2011 and 20062011, respectively) along with data from the ERA-Interim reanalysis.

We show that the zonal vertical distribution of cloud fraction anomalies averaged over $67-82^{\circ} \mathrm{N}$ to a first approximation follows a dipole structure (referred to as "Greenland cloud dipole anomaly", GCDA), such that during the positive phase of the AO, positive and negative cloud anomalies are observed eastwards and westward of Greenland respectively, while the opposite is true for the negative phase of AO. By investigating the concurrent meteorological conditions (temperature, humidity and winds), we show that differences in the meridional energy and moisture transport during the positive and negative phases of the $\mathrm{AO}$ and the associated thermodynamics are responsible for the conditions that are conducive for the formation of this dipole structure. All three satellite sensors broadly observe this large-scale GCDA despite differences in their sensitivities, spatio-temporal and vertical resolutions, and the available lengths of data records, indicating the robustness of the results. The present study
\end{abstract}

also provides a compelling case to carry out process-based evaluation of global and regional climate models.

\section{Introduction}

The Arctic Oscillation (AO), also sometimes referred to as the Northern Annular Mode, or NAM (Thompson and Wallace, 1998), is the leading natural mode of variability in the Northern Hemisphere atmospheric circulation (e.g., Perlwitz and Graf, 1995; Thompson and Wallace, 1998; Baldwin and Dunkerton, 1999; Christiansen, 2000). The spatial structure of this mode corresponds to the first empirical orthogonal function (EOF1) of the monthly averaged sea level pressure field and captures some of the large-scale dynamical properties of the atmosphere in the NH midlatitudes (Thompson and Wallace, 2000, 2001). The AO displays a dipole structure between the polar region and the midlatitudes and is the most important mode in winter. The largest meridional difference is found in the Atlantic sector and the well known North Atlantic Oscillation (NAO; e.g., Hurrell, 1995) is sometimes considered a regional manifestation of the $\mathrm{AO}$. The temporal evolution of the $\mathrm{AO}$ is described by the $\mathrm{AO}$ index, where large values are associated with a stronger-thanusual zonal flow in the midlatitudes, advecting warm air from the oceans to over the continents, thereby implying warmer than usual winter conditions over land, and large negative values imply a weaker zonal and a stronger meridional flow structure. For example, an increase in storm frequency over the northeast Northern Atlantic Ocean (e.g., Greenland and 
Norwegian Seas) is often associated with positive phases of the AO, while during negative phases, the low pressure systems over the North Atlantic Ocean often advance towards the southern Europe mid-latitudes and northern Europe has colder than average winters. Examples of strongly negative AO-conditions are the 2009-2010 and 2010-2011 winters that were rich in snow and cold conditions in Europe and Russia as well as along the Eastern US seaboard.

It has been well established that the Arctic Oscillation (AO) exerts a considerable influence on many climate variables in the mid-to-high latitudes in the NH. In fact, almost $50 \%$ of the observed trend in the several climate variables can be explained by the trend in the AO (Thompson et al., 2000). However, since then, Cohen and Barlow (2005) examined NAO and AO trends over the period 1958-2004 and showed that there is weak to non-existent trend over that period in spite of winter warming trend, the latter being unrelated to the NAO/AO. A similar result was found by Semenov et al. (2008) who also showed that trends, e.g., similar to those observed in 1965-1995, can be reproduced by the model and can be generated by internal variability.

Many studies have related changes in Arctic to the AO, for example in sea ice cover or motion (Rigor et al., 2002; Deser et al., 2000; and Kwok, 2000), in ocean circulation (Dickson et al., 2000), surface temperatures and clouds (Wang and Key, 2005). Few studies during the last decade attempted to provide plausible mechanisms for the AO. Life-cycles of about two weeks of these oscillations were explained as anticyclonic (cyclonic) breaking of low frequency synoptic-scale waves, their remnants forming the positive (negative) NAO phases by Benedict et al. (2004). Further studies by Strong and Magnusdottir (2008) showed a similar result, adding that at lower latitudes the cyclonicity of waves breaking changes for the two NAO phases, while Woolings et al. (2008) explain the same life cycle's two phases as a basic (positive phase) and perturbed (negative) by variations in upper level Rossby waves breaking.

Although our understanding of the $\mathrm{AO}$ at shorter time scales and the estimations of its large-scale impact on weather are improving, insufficient description of clouds and their dynamical coupling with the large-scale meteorology in climate and short-term forecast models, especially over the Arctic, still remains a major stumbling block in achieving the desired accuracy and confidence (Tjernström et al., 2008; Vavrus et al., 2008; Karlsson and Svensson, 2011; Svensson and Karlsson, 2011; Kay et al., 2012). In this context, knowledge of the vertical distribution of clouds during the different phases of the AO is crucial considering the tight connection of clouds with atmospheric circulation, thermodynamics and radiation. For example, the poor representation of vertical distribution of clouds in models may result in inaccurate simulations of storm track and intensity. Hence, it is of primary importance that we understand how cloud distribution is influenced by the AO.
Surface-based measurements of cloud vertical distribution are only available over a few locations in the Arctic (Shupe et al., 2011 and references therein). Some of the previous studies investigate co-variability among different atmospheric and surface parameters with the AO or the North Atlantic Oscillation (NAO) over the high latitude regions and the role of synoptic scale processes therein (Park and Leovy, 2000; Trigo et al., 2002; Hurrell et al., 2003; Wang and Key, 2003; Previdi and Veron, 2007; and references in these studies). However, very few studies examine how cloud distribution is influenced by the AO. Park and Leovy (2000) were first to use ship observations of cloudiness to show that an increase in bad weather stratiform and convective clouds over the northeast Atlantic during the positive Northern Hemisphere annular mode (NAM). Their observations, however, were restricted to below roughly $60^{\circ} \mathrm{N}$. Trigo et al. (2002) used NCEP reanalysis data to show increase in precipitable water over northern Europe and decrease over Greenland and northern Canada during high NAO index periods; and vice versa during the low NAO periods. Previdi and Veron (2007) used regional climate model to show similar spatial co-variability in cloud liquid and ice water path and the NAO. They also use satellite based observations of total cloud fraction (2-D) to check the consistency of their modelling results. However, the detailed investigations of how the 3-D distribution of clouds manifests itself during high and low phases of the AO over the Arctic based purely on observations are still lacking. Therefore, in the present study, we build upon the advantages of NASA's Afternoon Train (ATrain) constellation of satellites (L'Ecuyer and Jiang, 2010) and, for the first time, quantify the relationships between the $\mathrm{AO}$ on the cloud 3-D distribution over northern high latitude regions. One of the unique aspects of the A-Train constellation is the sensing of vertical distribution of clouds along with a suite of other atmospheric variables. This gives an opportunity to explore the meteorological context of the clouds without introducing biases related to inconsistent time and space sampling while providing nearly complete coverage of the Arctic. The paper is organized as follows. Section 2 provides descriptions of the data sets used in this study followed by a discussion of the results in Sect. 3. The conclusions are presented in the final Sect. 4.

\section{The data}

In the present study we used data from three different instruments flying onboard the A-Train constellation of satellites: Aqua, CALIPSO and CloudSat. We also employ data from the ERA-Interim reanalysis.

\subsection{AIRS}

The Atmospheric Infrared Sounder (AIRS)/Advanced Microwave Sounding Unit (AMSU) instrument suite has 
produced geophysical retrievals of temperature, water vapor, atmospheric and surface properties, and minor gases since September 2002 using a cloud clearing approach (Chahine et al., 2006). The AIRS grating spectrometer has a total of 2378 infrared channels, with a spectral coverage between 3.7 and $15.4 \mu \mathrm{m}$ (there are two gaps between 4.6-6.2 $\mu \mathrm{m}$ and $8.2-8.8 \mu \mathrm{m})$. The AIRS temperature and water vapor profiles are calculated at approximately $\sim 40 \mathrm{~km}$ spatial resolution at nadir view and this is termed the AIRS "field of regard" (FOR). In the AIRS Version 5 algorithm, the cloud top pressure is retrieved in up to two layers at the AIRS FOR resolution, while the effective cloud fraction is retrieved in up to two layers on the individual AIRS FOVs $(\sim 13.5 \mathrm{~km}$ at nadir view). As AIRS scans in both directions to $49.5^{\circ}$ off nadir, this facilitates near-global coverage on a daily basis. The Level-2 geophysical products are re-gridded (in space and time) to a Level-3 (L3) product. Herein, the AIRS Daily L3 Version 5 (V5) Standard Product is used. This AIRS L3 product reports effective cloud fraction (emissivity convolved with cloud fraction) at 12 pressure levels from $1000 \mathrm{hPa}$ up to $100 \mathrm{hPa}$. Nearly a decade of data, from December 2002 through March 2011, is used in this study. In addition to clouds, the retrievals of temperature, water vapour, and geopotential height are also analysed to understand the observed variability in the cloud vertical structure. Over the years, AIRS data sets have matured considerably and a wealth of literature on the validation of AIRS retrievals, including cloud products, is now available (e.g., Divakarla et al., 2006; Fetzer, 2006; Kahn et al., 2008; Nasiri et al., 2010). This daily L3 standard product has previously been used for studying large-scale climatic features over the high latitudes (Devasthale et al., 2010, 2011a).

\subsection{CALIPSO}

The Cloud and Aerosol Lidar with Orthogonal Polarization (CALIOP) instrument onboard the Cloud-Aerosol Lidar and Infrared Pathfinder Satellite Observations (CALIPSO) satellite and the Cloud Profiling Radar (CPR; see below) instruments onboard the CloudSat satellite provide the most complete set of global observations of vertical cloud structure to date (Winker et al., 2009). These data sets are mature enough to facilitate the investigation of the large-scale statistics and processes at high latitudes (e.g., Devasthale et al., 2011b). In the present study we use the standard CALIPSO $5 \mathrm{~km}$ Cloud Layer Version 3.01 product. Among all data quality flags provided in the data set, a stringent quality control configuration is used by selecting only high confidence estimates. For example, based on the information in the feature classification flags, the retrievals are used only if the quality of feature classification is set to "high" and cloud phase discrimination quality (Hu et al., 2009) is also set to "high". The data used here cover a period from June 2006 through March 2011.

\subsection{CloudSat}

The radar reflectivities obtained from the active CPR instrument operating at $94 \mathrm{GHz}$ frequency onboard CloudSAT form the basis for a number of products providing information on cloud physical and microphysical properties (Stephens et al., 2002; Marchand et al., 2008). We used the standard 2B-GEOPROF-LIDAR product that is the most representative view of the vertical profiles of clouds by combining the strengths of 2B-GEOPROF product and CALIPSO V2 vertical feature mask (Mace et al., 2007). The CloudSat radar and CALIPSO lidar are complementary (Mace et al., 2007). The radar penetrates through most thick clouds except for heavy precipitation, and observes the layers of precipitation that may not be observed by the lidar, while the lidar captures thin cloud layers that are below the detection limits of the radar, and adds cloud information in the lowermost 1$\mathrm{km}$ in the troposphere where the radar signal as adversely affected by ground clutter. Data from the 2B-GEOPROFLIDAR product from June 2006 through May 2011 is used in this analysis.

\subsection{The ERA-Interim reanalysis}

A reanalysis is the optimal blend of observations and numerical model data; the model provides consistency and timeand-space continuity while the data corrects for model errors in a cycle of data assimilations. The quality of reanalysis products varies depending on the variables considered and the density of observations in a particular area. More observations and considering variables closer to those directly constrained by observations provide higher quality. While several reanalysis datasets exist, we use the ERA-Interim reanalysis data in this investigation (Dee et al., 2011). Zonal and meridional wind components are extracted directly from the reanalysis in order to investigate circulation patterns and their effect on the transport of energy over the pan-Arctic region.

\subsection{The definitions of the selected AO phases}

The strength of the $\mathrm{AO}$ is often expressed in terms of so-called AO Index (AOI) at daily, monthly or seasonal time scales. We used the daily AOI values from December 2002 for AIRS data analysis and from November 2006 for the CloudSat and CALIPSO data analysis, in both cases extending through March 2011. These data were obtained from NOAA's Climate Prediction Center's (CPC) website (http://www.cpc.ncep.noaa.gov/ products/precip/CWlink/daily_ao_index/ao.shtml).

Figure 1 shows the time series of daily AOI. The time series shows the seemingly random fluctuations in AOI with infrequent excursions to very high values (winters of 2004/2005 and 2006/2007) and extremely low values (winters of 2009/2010 and 2010/2011). The long-term value is 


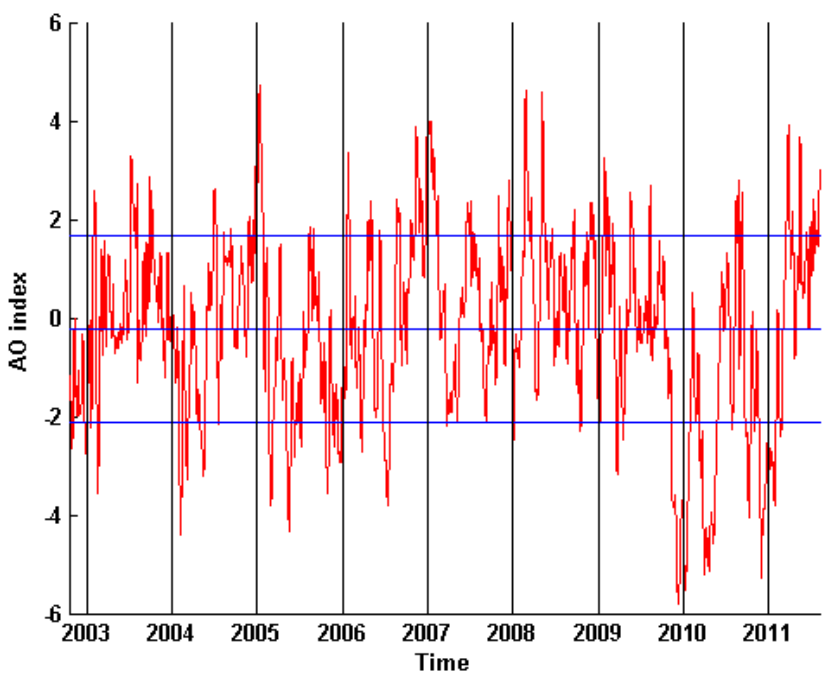

Fig. 1. The daily AO index for the months of NDJFM each year from December 2002 till March 2011. The blue line in the center is mean $\mathrm{AO}$ index for the chosen time period, while other two blue lines above and below indicate one standard deviation.

close to zero. From these data we define the following four AO-phases for our analysis.

- CP: climatological positive phase when AOI is positive

- CN: climatological negative phase when AOI is negative

- EP: enhanced positive phase, when AOI is larger than one standard deviation above zero

- EN: enhanced negative phase, when AOI is smaller than one standard deviation below zero

Note that $\mathrm{EP}(\mathrm{EN})$ is included in $\mathrm{CP}(\mathrm{CN})$ so that the sample is much larger for $\mathrm{CP}$ and $\mathrm{CN}$ than for the two enhanced phases.

\section{Results and discussions}

Figure 2 shows the geopotential height anomalies at $200 \mathrm{hPa}$ derived from AIRS data during the four phases of the AO. Below average anomalies during CP show the typical signature of an increased meridional gradient that results in strengthening of the polar vortex around the Arctic; the EP pattern amplifies this further. The positive anomalies during the $\mathrm{CN}$ and EN phases instead feature a reduced gradient, weakening of the polar vortex and allowing cold Arctic air to more easily reach the mid-latitudes (e.g., Overland et al., 2011).

This see-saw pattern in the atmospheric circulation during positive and negative phases of $\mathrm{AO}$ also has influences on the cloud distribution through its large-scale control of the atmospheric thermodynamics. Figure 3 provides an overview of
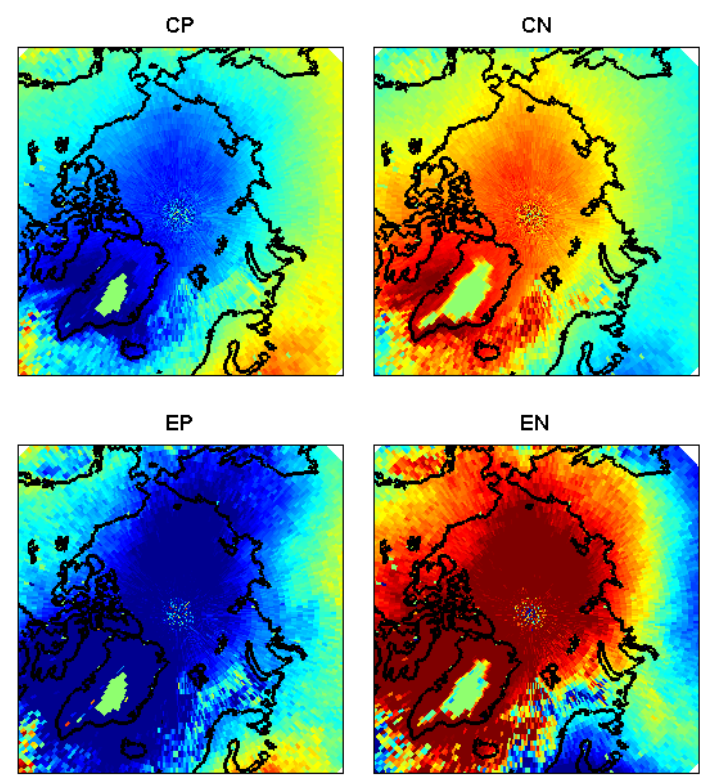

$-100$

50

0

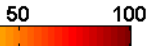

Fig. 2. The AIRS-derived geopotential height anomalies (in meters) at $200 \mathrm{hPa}$ showing typical signatures of the strong and weak strengths of polar vortex during the chosen four phases of the AO.
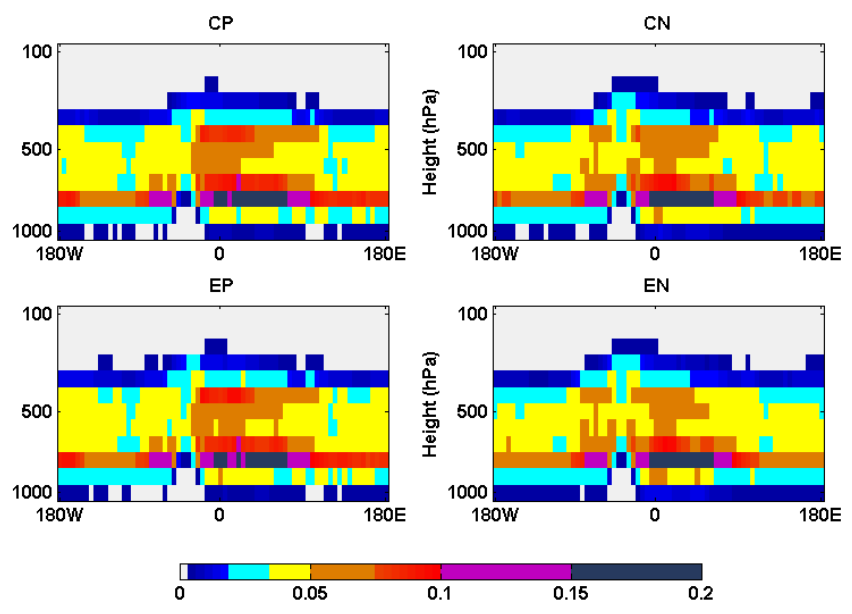

Fig. 3. Climatological effective cloud fraction derived from AIRS (2002-2011) averaged over $67-82^{\circ} \mathrm{N}$. Note that the colourbar is adapted to highlight differences in cloud fraction.

zonal vertical effective cloud fraction from AIRS for the previously defined four phases of the AO. These cross-sections show that the greatest values of effective cloud fraction occur on the eastern side of Greenland over the ocean, with most clouds between the surface and $500 \mathrm{hPa}$. Figures 4-8 show the zonal and vertical distribution of cloud fraction anomalies averaged over $67-82^{\circ} \mathrm{N}$ using AIRS, CALIPSO and CloudSat data sub-sampled according to the various phases of the $\mathrm{AO}$, as defined in Sect. 2.5. For each height-longitude bin, 
$\mathrm{CP}$
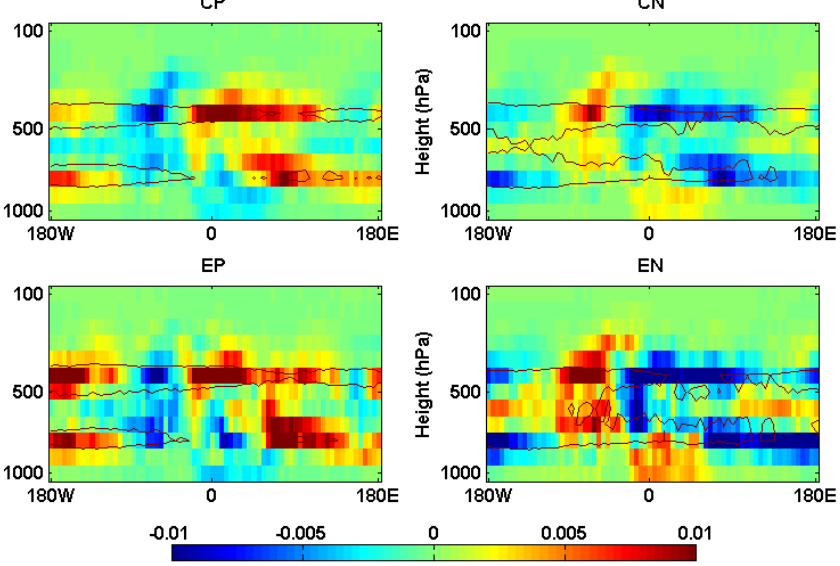

Fig. 4. The vertical distribution of cloud fraction anomalies derived using AIRS data across $180^{\circ} \mathrm{W}-180^{\circ} \mathrm{E}$ (in $5^{\circ}$ bins) averaged over $67-82^{\circ} \mathrm{N}$ during various phases of the AO. Anomalies enclosed by contours exceed at least one standard deviation.

these anomalies are calculated by taking the difference of cloud fraction during a particular AO phase and the climatological cloud fraction covering November through March of all years for which respective data sets are available, as mentioned in Sect. 2. Note that the data from AIRS are analyzed only up to $82^{\circ} \mathrm{N}$ although this sensor has polar coverage. We maintain the geophysical consistency with CloudSat and CALIPSO, which cannot sample poleward of this latitude. Figure 4 shows cloud fraction anomalies from AIRS for the different AO-phases. When the AO is positive, positive anomalies are observed eastward of Greenland (located at longitude $40^{\circ} \mathrm{W}$ ) in the middle and upper troposphere (300$500 \mathrm{hPa}$ ), while lower tropospheric clouds $(700-800 \mathrm{hPa})$ have a positive anomaly eastward of Northern Scandinavia and around to the Canadian archipelago; negative anomalies are evident directly westward of Greenland throughout the whole troposphere and also for the very lowest clouds $(\sim 1000 \mathrm{hPa})$ over the Nordic Sea. The EP phase of the AO displays a more enhanced pattern than for the $\mathrm{CP}$ phase. The negative $\mathrm{CN}$ and $\mathrm{EN}$ phases, however, feature precisely the opposite pattern of anomalies; their patterns are virtually a mirror image of the patterns for the positive AO. Hereafter this see-saw pattern in anomalies during positive and negative phases of the AO is referred to as the "Greenland cloud dipole anomaly (GCDA)" pattern.

Figure 5 shows the cloud anomalies based on the CALIPSO data. Although there are some differences in the details compared to Fig. 4, the anomaly patterns for ice clouds are broadly similar to the GCDA observed for total cloud fraction. Note that the heights of the GCDA as observed by AIRS are lower by roughly $1-3 \mathrm{~km}$ compared to CALIOP-CALIPSO. This is primarily due to different sensitivities of these two instruments to different cloud types (Kahn et al., 2008). For example, while CALIOP locates the
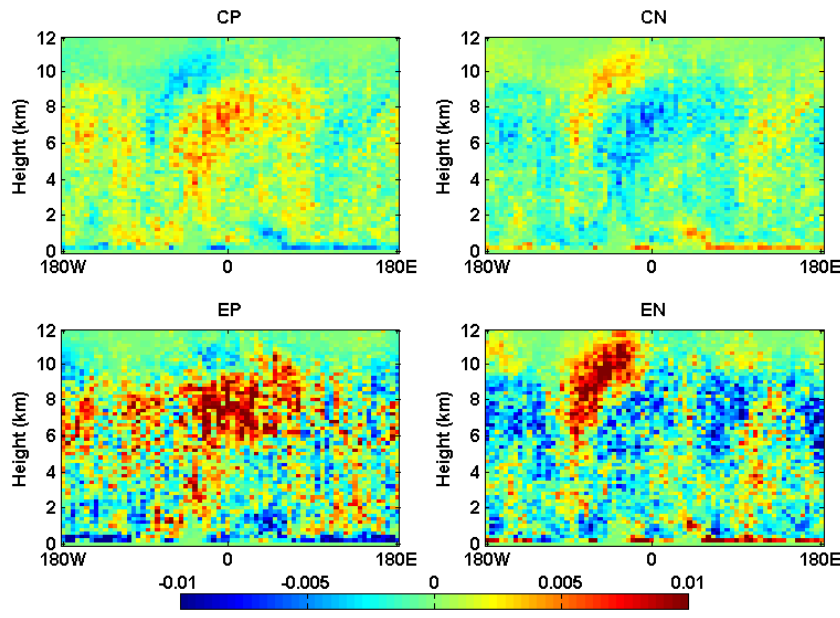

Fig. 5. Same as Fig. 4, but for clouds derived using CALIPSO data.

"true" top of a cirrus cloud, the AIRS height will be within the cloud at some variable depth depending on the vertical structure of cloud hydrometeors (Holz et al., 2006). The limited spatial sampling of CALIPSO and shorter length of data record compared to AIRS may also have contributed to the patchy nature of the observed anomalies, but nevertheless, the large-scale footprint of GCDA is evident in the CALIPSO data, especially for $\mathrm{CP}$ and $\mathrm{CN}$. However, while the pattern of $\mathrm{EN}$ cloud anomalies is an amplified version of the $\mathrm{CN}$ pattern, the EP cloud anomalies shows an enhanced but also more complex pattern than CP. Thus, while the CP pattern is close to a mirror image of the $\mathrm{CN}$ pattern, that is not the case for the EP and the EN patterns. The CALIOP EP pattern appears to be the most "different" of the four AO groupings.

From the perspective of thermodynamics and the radiation budget, it is important to determine whether liquid and/or ice phase clouds are similarly influenced by the AO. However, the explicit information on cloud phase is not available in the V5 AIRS data. The depolarization measurements from the CALIOP lidar provide quantitatively useful information on cloud phase. Spherical liquid droplets are in general more weakly depolarizing than the randomly oriented ice crystals. This property of the backscattered light can be exploited to derive cloud phase. However, horizontally oriented ice crystals in ice clouds can also depolarize weakly, while the multiple scattering by water droplets could lead to high depolarization in liquid water clouds. In order to address this, the CALIOP cloud phase detection algorithm is improved by $\mathrm{Hu}$ et al. (2009) resulting in the best identification of cloud phase among the sensors used here.

Since the GCDA is most pronounced in the higher troposphere, we first investigated the vertical structure of ice phase clouds from CALIPSO (see Fig. 6). The dipole pattern in ice clouds for CP appears somewhat shifted in strength so that there is a larger positive anomaly east of Greenland and a weaker anomaly west thereof. For the stronger positive 

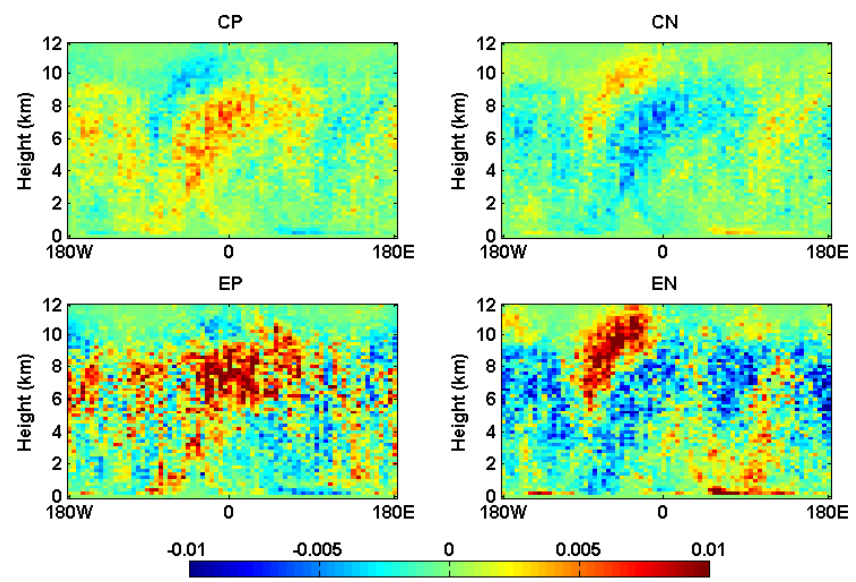

Fig. 6. Same as Fig. 5, but for only for ice phase clouds derived using CALIPSO data.

AOI there is also less of an anomaly dipole; while the positive anomaly is still clearly visible there is also a more widespread positive anomaly around $6-8 \mathrm{~km}$ and the negative anomaly west of Greenland weakly visible for $\mathrm{CP}$ has vanished in EP. For the negative phase of the AOI, the ice cloud anomaly is reversed, as for total clouds, and dipole is more symmetric than for the positive AOI. As the AOI becomes more strongly negative the positive anomaly west of Greenland dominates; there is still a negative anomaly east of Greenland but also other more widespread areas of negative anomalies.

Figure 7 shows the anomalies for only water phase clouds. The dipole structure in the free troposphere similar to that of Figs. 4 and 6 is also evident in Fig. 7. Due to the high vertical resolution of CALIPSO compared to AIRS, the cloud fraction anomalies in the lowermost $1-2 \mathrm{~km}$ are more clearly visible in Fig. 7 than in Fig. 4. Nonetheless, it is encouraging to note that, despite fundamental differences, both data sets show similar pattern of cloud fraction anomalies eastward of Greenland in the lowermost troposphere (between $500 \mathrm{~m}$ to $2 \mathrm{~km}$ ). The cloud fraction anomalies below $200 \mathrm{~m}$ in Fig. 7 are most likely artefacts due to limited sampling.

Neither AIRS nor CALIOP can penetrate through optically thick clouds. Therefore, the most faithful description of the cloud vertical structure through most of the troposphere can be obtained from CloudSat due to its ability to fully penetrate through thick clouds. Most of the low level clouds over the Arctic are observed below the lowest one kilometer of the troposphere (Devasthale et al., 2011b; Shupe et al., 2011). However, as mentioned in Sect. 2.3, the CloudSat reflectivities are affected by ground clutter in the lowermost kilometre, thus masking the majority of these clouds. Because CALIPSO has limited ground clutter, it complements the CloudSat data in the combined profile product 2BGEOPROF-LIDAR used here, at least for the single-layer low clouds where the lidar is no attenuated before it reaches
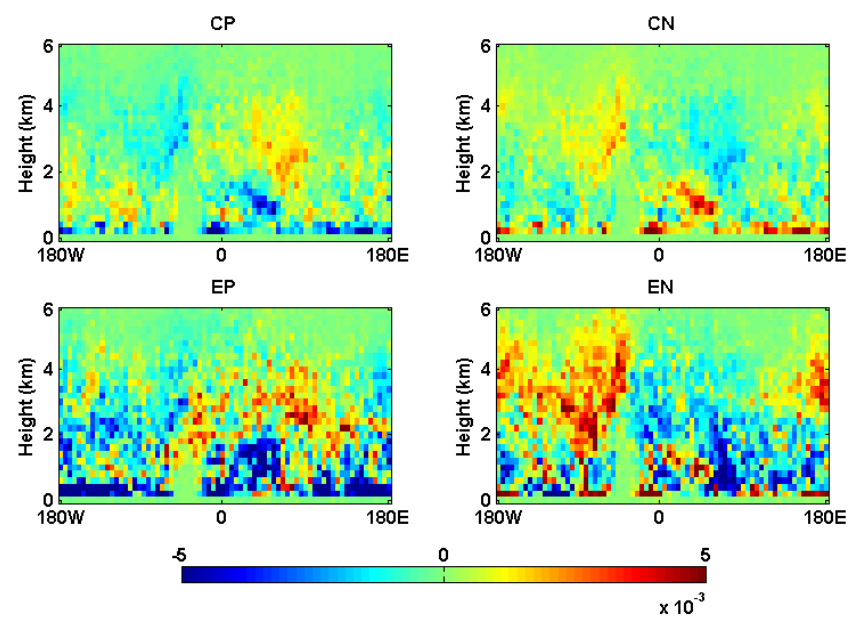

Fig. 7. Same as Fig. 5, but only for liquid phase clouds derived using CALIPSO data.
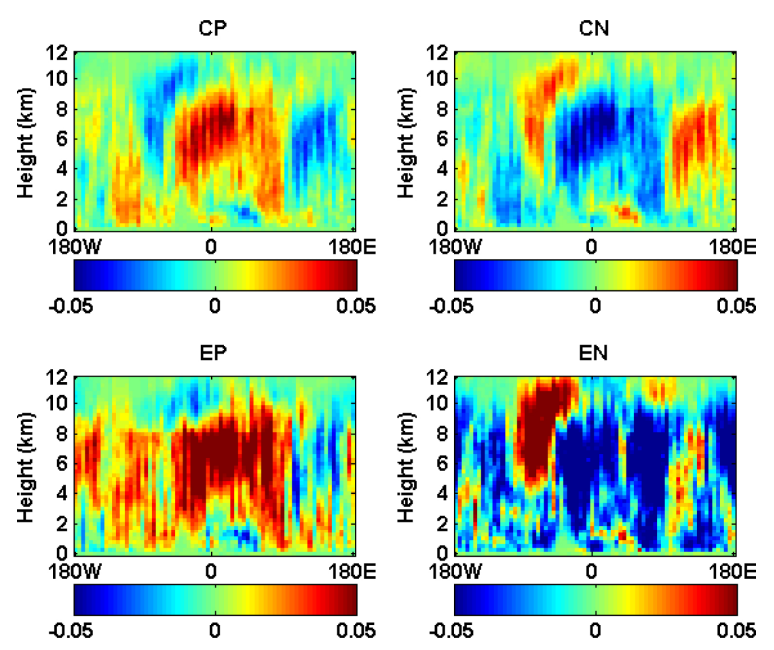

Fig. 8. Same as in Fig. 4, but using combined CloudSAT-CALIPSO data.

the lowest heights. Figure 8 shows that the anomaly patterns as observed by AIRS and CALIPSO are also evident in the combined CloudSat-CALIPSO data. In this combined dataset, the GCDA pattern is clearly visible for the $\mathrm{CP} / \mathrm{CN}$ cases, while for the larger AOI (regardless of sign) the pattern is dominated by the positive (negative) anomaly for the EP (EN) cases although the dipole is still present. Furthermore, the differences previously noted in EP compared to the other AO categories in the CALIOP data (Fig. 5) are much more pronounced in Fig. 8. This suggests that the AO strongly modulates the behaviour of deep precipitating systems in the GCDA, not just ice clouds in the upper troposphere.

In summary, the three satellite sensors with very different sensitivities, horizontal and vertical resolutions, and also covering two different time periods, provide a broadly similar and consistent description of the changes in the cloud spatial structure during different phases of the AO. This 
EP

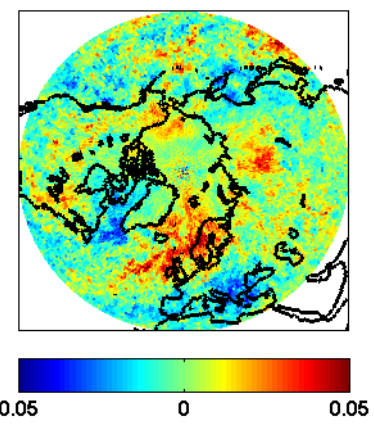

EN

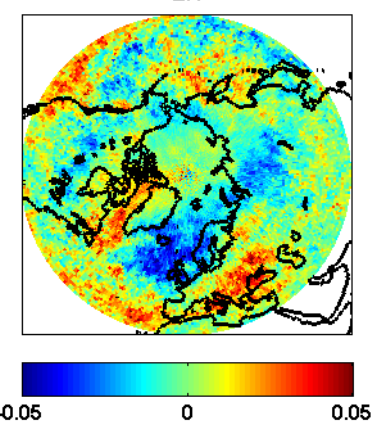

Fig. 9. Cloud fraction anomalies derived using AIRS data at $400 \mathrm{hPa}$ for the EP and EN cases show a 2-D manifestation of the Greenland Cloud Dipole Anomaly (GCDA) in the middle troposphere.

consistency suggests that the observed cloud anomaly pattern as a function of $\mathrm{AO}$ is a robust feature.

We propose that the main mechanism leading to the observed vertical cloud fraction anomalies entails different large-scale advection patterns on either side of Greenland during positive and negative phases of the AO. The North Atlantic Ocean is a common pathway for winter storms travelling east and northeast (Serreze and Barry, 1988; Hoskins and Hodges, 2002). During positive phases of the AO the frequency of storms in the North Atlantic Ocean increases and storminess extends far northeast over the Greenland, Norwegian and into the Kara Seas. These large-scale changes in atmospheric circulation and thermodynamics will directly influence the cloud cover over these regions. For example, Fig. 9 shows effective cloud fraction anomalies derived using AIRS data for the EP and EN cases at $400 \mathrm{hPa}$, the height at which GCDA is strongest and the advection of energy and moisture is most likely to be enhanced during the positive AO phases. This figure clearly shows a 2-D manifestation of the dipole structure, wherein positive (negative) anomalies are visible eastward (westward) of Greenland. The Central Siberian and Northeast Asian regions also show anomalies of opposite nature during the EP and EN phases; however, their spatial extent is not as large as over the dipole feature region in the North Atlantic. Figure 10 shows the zonal and meridional wind components at $500 \mathrm{hPa}$ during the EP and EN phases. During EP both wind components are strongly positive over the northern North Atlantic compared to the EN phase, bringing more heat and moisture into the Arctic. The positive meridional component of wind during EP is especially strong over the Greenland and Norwegian Seas suggesting increased northward transport of water vapour and heat over these regions. That this is indeed the case is displayed in Fig. 11, which shows AIRS water vapour mixing ratios and temperature anomalies. These anomalies also show a clear dipole structure. This is consistent with the study by Groves and Francis (2002) where they show a clear increase in the precipitable water eastward of Greenland and
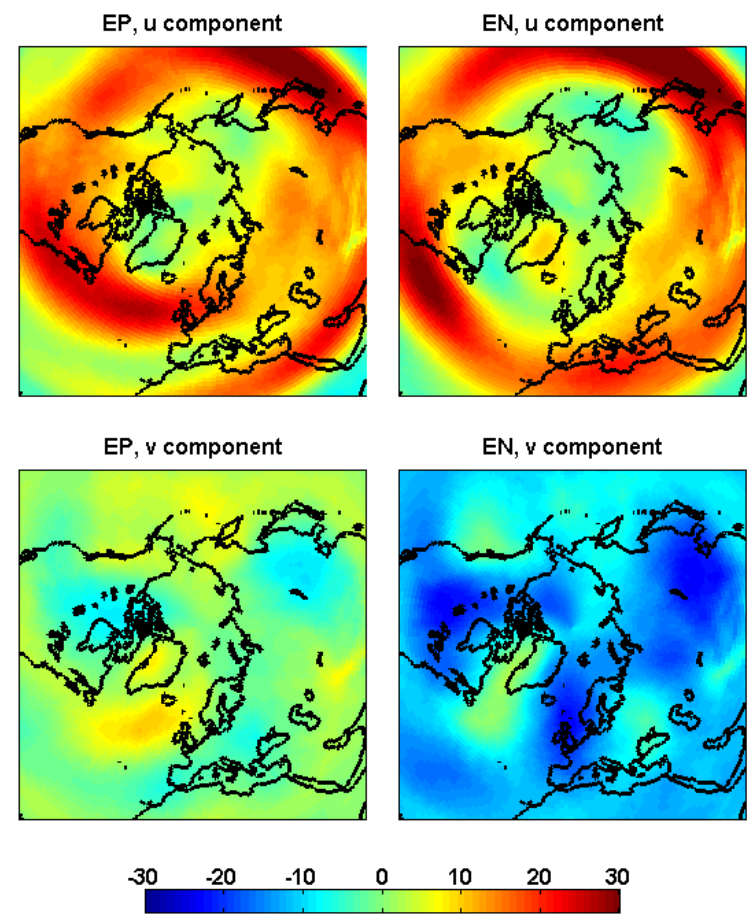

Fig. 10. The mean zonal and meridional components of winds computed using ERA-Interim reanalysis data during the EN and EP phases.
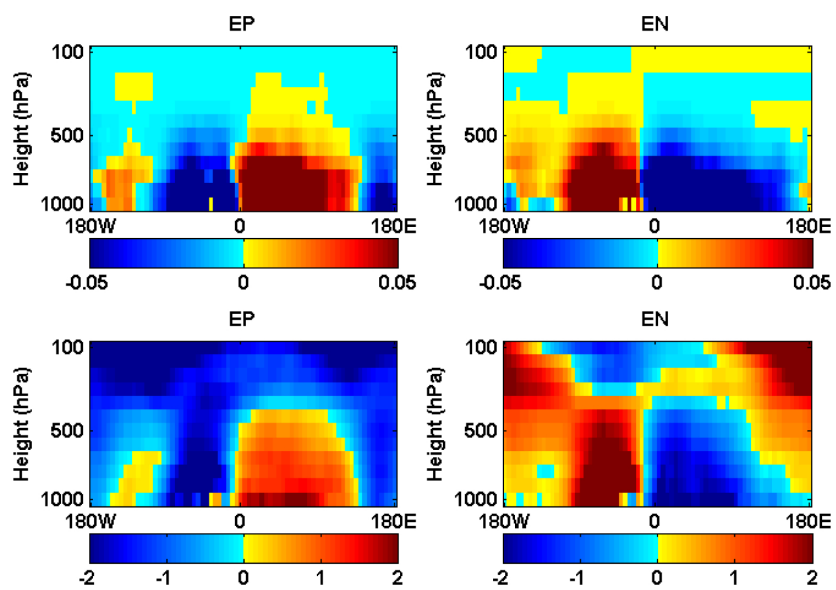

Fig. 11. The vertical distribution of water vapour mass mixing ratio anomalies $\left(\mathrm{g} \mathrm{kg}^{-1}\right)$ (top row) and temperature anomalies (in $\mathrm{K}$ ) derived using AIRS data averaged over $67-82^{\circ} \mathrm{N}$ during the EP and EN phases of the AO.

a decrease westward during days with high AOI, and vice versa during days with low AOI.

All of these results suggest that the conditions are conducive for the formation and sustenance of clouds (especially mid- and high level clouds) over the northeast Atlantic during the positive phases and vice versa, thus explaining the observed GCDA in all three cloud data sets. 


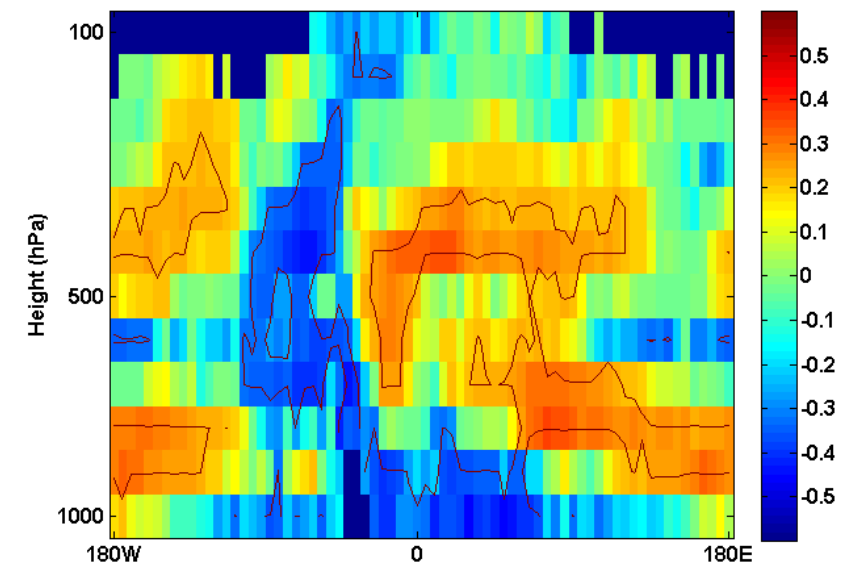

Fig. 12. Correlation of AIRS derived daily effective cloud fraction anomalies (for the NDJFM period; with respect to 2002-2011 climatology) with the daily AO index. The contours show regions with correlations observed at $95 \%$ confidence level.

In order to assess statistical significance of the dipole feature, we further analyzed nine winter half-years (NDJFM) of AIRS effective cloud fraction data. Since the emphasis of the present study lies on a spatial feature space, a field significance test is an appropriate metric to assess statistical significance (Livezey and Chen, 1983; DelSole and Yang, 2011). For each longitude-height bin, we derived cloud fraction anomalies (with respect to 2002-2011 climatology) and investigated their correlations with the $\mathrm{AO}$ index. The result of this analysis is shown in Fig. 12. The area enclosed by contours show regions where correlations are locally observed at $95 \%$ confidence level. We then applied a Monte Carlo technique as suggested in the classical article by Livezey and Chen (1983). The test is carried out as follows. We calculated the areal percentage in Fig. 12 where correlations of cloud anomalies (derived from AIRS data) with the AO index are significant at $95 \%$ confidence level. This areal percentage is $14.7 \%$. Then the daily time series of the $\mathrm{AO}$ index for the NDJFM 2002-2011 period is replaced by 1000 random simulations selected from a normal distribution. These 1000 time-series' were correlated with cloud fraction anomalies in the height-longitude space one at a time and the areal percentage where correlations are significant at $95 \%$ confidence level is calculated. The histogram of these percentages is shown in Fig. 13 and the shaded area corresponds to the $5 \%$ tail. Since less than $5 \%$ of the 1000 simulations have their areal percentages greater than 14.7 at $95 \%$ confidence level, it is possible to reject the hypothesis that the observed Greenland Cloud Dipole Anomaly structure is just a chance occurrence. Based on this result along with the thermodynamical context for GCDA as discussed before, we argue that the GCDA is a robust physical feature.

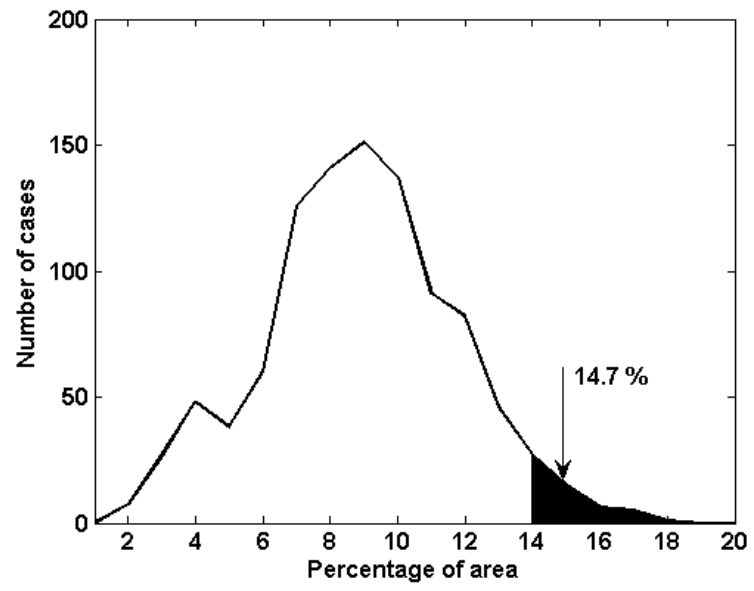

Fig. 13. Histogram of percentage of area where correlations of cloud anomalies with Gaussian noise is locally statistically significant at $95 \%$ level in 1000 Monte Carlo simulations. The shaded area shows $5 \%$ tail. Refer text for further description.

\section{Conclusions}

In order to accurately improve our understanding of the Arctic Oscillation (AO) and its large-scale impact on weather and climate, it is crucial to understand how the vertical distribution of clouds is influenced by the $\mathrm{AO}$ and whether this behaviour is faithfully simulated by models. A few of the sensors onboard the NASA's A-Train convoy of satellites provided a detailed description of the cloud vertical structure that enabled us to investigate the influence of the AO on spatial distributions of Arctic cloud based solely on observations. For the first time, it was found that the zonal vertical distribution of cloud fraction anomalies over the western hemisphere and averaged over $67-82^{\circ} \mathrm{N}$ follows a dipole structure (referred to as the "Greenland cloud dipole anomaly", GCDA). During the positive phase of the AO, increased cloudiness is observed eastwards of Greenland with clearer conditions westward, while the opposite is observed during the negative phase of the AO. The differences in energy and moisture transport towards the Arctic during the positive and negative phases of the $\mathrm{AO}$, and associated thermodynamics, lead to conditions that are conducive to the formation of such a dipole cloud structure. It is worth pointing out that the three sensors (Aqua-AIRS, CALIOPCALIPSO and CPR-CloudSat) with different sensitivities and spatial and vertical resolutions and covering two different time periods (2006-2011, 2002-2011) show features that are broadly consistent. While highlighting the usefulness of synergy among various A-Train sensors, the present study also provides a compelling metric to carry out a processbased evaluation of global and regional climate models in the high Arctic latitudes. 
Acknowledgements. Authors would like to thank two anonymous referees for their constructive remarks and Grigory Nikulin (Rossby Center for Climate Research, SMHI) for discussions regarding field significance test. We also acknowledge the efforts of A-Train Science Teams and data centers (NASA's ASDC and GES DISC, CloudSat DPC, and ECMWF data portal) for making data sets publicly available for research. This work was funded by Swedish National Space Board.

Edited by: T. Garrett

\section{References}

Baldwin, M. P. and Dunkerton, T. J.: Downward propagation of the Arctic Oscillation from the stratosphere to the troposphere, J. Geophys. Res., 104, 30937-30946, 1999.

Benedict, J. J., Lee, S., and Feldstein, S. B.: Synoptic view of the North Atlantic Interactive Oscillation, J. Atmos. Sci., 61, 121144, 2004.

Chahine, M. T., Pagano, T. S., Aumann, H. H., Atlas, R., Barnet, C., Blaisdell, J., Chen, L., Divakarla, M., Fetzer, E. J., Goldberg, M., Gautier, C., Granger, S., Hannon, S., Irion, F. W., Kakar, R., Kalnay, E., Lambrigtsen, B. H., Lee, S.-Y., Le Marshall, J., McMillan, W. W., McMillin, L., Olsen, E. T., Revercomb, H., Rosenkranz, P., Smith, W. L., Staelin, D., Strow, L. L., Susskind, J., Tobin, D., Wolf, W., and Zhou, L.: AIRS: Improving Weather Forecasting and Providing New Data on Greenhouse Gases, B. Am. Meteorol. Soc., 87, 911-926, 2006.

Christiansen, B.: On the physical nature of the Arctic Oscillation, Geophys. Res. Lett., 29, 1805, doi:10.1029/2002GL015208, 2002.

Cohen, J., and Barlow, M.: The NAO, the AO, and Global Warming: How Closely Related?, J. Climate, 18, 4498-4513, doi:10.1175/JCLI3530.1, 2005.

Dee, D. P., Uppala, S. M., Simmons, A. J., Berrisford, P., Poli, P., Kobayashi, S., Andrae, U., Balmaseda, M. A., Balsamo, G., Bauer, P., Bechtold, P., Beljaars, A. C. M., van de Berg, L., Bidlot, J., Bormann, N., Delsol, C., Dragani, R., Fuentes, M., Geer, A. J., Haimberger, L., Healy, S. B., Hersbach, H., Hólm, E. V., Isaksen, L., Kållberg, P., Köhler, M., Matricardi, M., McNally, A. P., Monge-Sanz, B. M., Morcrette, J.-J., Park, B.-K., Peubey, C., de Rosnay, P., Tavolato, C., Thépaut, J.-N., and Vitart, F.: The ERA-Interim reanalysis: Configuration and performance of the data assimilation system, Q. J. Roy. Meteor. Soc., 137, 553-597, doi:10.1002/qj.828, 2011.

DelSole, T. and Yang, X.: Field Significance of Regression Patterns, J. Climate, 24, 5094-5107, 2011.

Deser, C., Walsh, J. E., and Timlin, M. S.: Arctic sea ice variability in the context of recent atmospheric circulation trends, J. Climate, 13, 617-633, 2000.

Devasthale, A., Willén, U., Karlsson, K.-G., and Jones, C. G.: Quantifying the clear-sky temperature inversion frequency and strength over the Arctic Ocean during summer and winter seasons from AIRS profiles, Atmos. Chem. Phys., 10, 5565-5572, doi:10.5194/acp-10-5565-2010, 2010.

Devasthale, A., Sedlar, J., and Tjernström, M.: Characteristics of water-vapour inversions observed over the Arctic by Atmospheric Infrared Sounder (AIRS) and radiosondes, Atmos. Chem. Phys., 11, 9813-9823, doi:10.5194/acp-11-9813-2011, 2011a.
Devasthale, A., Tjernström, M., Karlsson, K-G., Thomas, M. A., Jones, C., Sedlar, J., and Omar, A. H.: The vertical distribution of thin features over the Arctic analysed from CALIPSO observations. Part I: Optically thin clouds, Tellus B, 63, 77-85, 2011b.

Dickson, R. R., Osborn, T. J., Hurrell, J. W., Meincke, J., Blindheim, J., Adlandsvik, B., Vinje, T., Alekseev, G., and Maslowski, W.: The Arctic Ocean response to the North Atlantic Oscillation, J. Climate, 13, 2671-2696, 2000.

Divakarla, M. G., Barnet, C. D., Goldberg, M. D., McMillin, L. M., Maddy, E., Wolf, W., Zhou, L., and Liu, X.: Validation of Atmospheric Infrared Sounder temperature and water vapor retrievals with matched radiosonde measurements and forecasts, J. Geophys. Res., 111, D09S15, doi:10.1029/2005JD006116, 2006.

Fetzer, E. J.: Preface to special section: Validation of Atmospheric Infrared Sounder Observations, J. Geophys. Res., 111, D09S01, doi:10.1029/2005JD007020, 2006.

Groves, D. G. and Francis, J. A.: Variability of the Arctic atmospheric moisture budget from TOVS satellite data, J. Geophys. Res., 107, 4785, doi:10.1029/2002JD002285, 2002.

Holz, R. E., Ackerman, S., Antonelli, P., Nagle, F., Knuteson, R. O., McGill, M., Hlavka, D. L., and Hart, W. D.: An improvement to the high spectral resolution $\mathrm{CO}_{2}$ slicing cloud top altitude retrieval, J. Atmos. Ocean. Tech., 23, 653-670, 2006.

Hoskins, B. J. and Hodges, K. I.: New Perspectives on the Northern Hemisphere Winter Storm Tracks, J. Atmos. Sci., 59, 10411061, 2002.

Hu, Y., Winker, D., Vaughan, M., Lin, B., Omar, A., Trepte, C., Flittner, D., Yang, P., Nasiri, S. L., Baum, B., Sun, W., Liu, Z., Wang, Z., Young, S., Stamnes, K., Huang, J., Kuehn, R., and Holz, R.: CALIPSO/CALIOP cloud phase discrimination algorithm, J. Atmos. Ocean. Tech., 26, 2293-2309 2009.

Hurrell, J. W.: Decadal trends in the North Atlantic Oscillation: Regional temperatures and precipitation, Science, 269, 676-679, 1995.

Hurrell, J. W., Kushnir, Y., Ottersen, G., and Visbeck, M. (Eds.): The North Atlantic Oscillation: Climate Significance and Environmental Impact, Amer. Geophys. Union Geophysical Monograph Series, 134, 279 pp., ISSN: 0065-8448; ISBN: 0-87590994-9, 2003.

Kahn, B. H., Chahine, M. T., Stephens, G. L., Mace, G. G., Marchand, R. T., Wang, Z., Barnet, C. D., Eldering, A., Holz, R. E., Kuehn, R. E., and Vane, D. G.: Cloud type comparisons of AIRS, CloudSat, and CALIPSO cloud height and amount, Atmos. Chem. Phys., 8, 1231-1248, doi:10.5194/acp-8-1231-2008, 2008.

Karlsson, J. and Svensson, G.: The simulation of Arctic clouds and their influence on the winter present-day climate in the CMIP3 multi-model dataset, Clim. Dynam., 36, 623-635, 2011.

Kay, J. E., Holland, M. M., Bitz, C. M., Blanchard-Wrigglesworth, E., Gettelman, A., Conley, A., and Bailey, D.: The Influence of Local Feedbacks and Northward Heat Transport on the Equilibrium Arctic Climate Response to Increased Greenhouse Gas Forcing, J. Climate, 25, 5433-5450, doi:10.1175/JCLI-D-1100622.1, 2012.

Kwok, R.: Recent changes in Arctic Ocean sea ice motion associated with the North Atlantic Oscillation, Geophys. Res. Lett., 27, 775-778, 2000.

L'Ecuyer, T. S. and Jiang, J.: Touring the Atmosphere Aboard the A-Train, Phys. Today, 63, 36-41, 2010. 
Livezey, R. E. and Chen, W. Y.: Statistical field significance and it's determination by Monte Carlo Techniques, Mon. Weather Rev., 111, 46-59, 1983.

Mace, G. G., Vane, D., Stephens, G., and Reinke, D.: Level 2 RadarLidar GEOPROF Product Version 1.0 Process Description and Interface Control Document, JPL, Pasadena, USA, 1-20, 2007.

Marchand, R. T., Mace, G., Ackerman, T., and Stephens, G.: Hydrometeor Detection using CloudSat - an Earth Orbiting 94 GHz Cloud Radar, J. Atmos. Ocean. Tech., 25, 519-533, doi:10.1175/2007JTECHA1006.1, 2008.

Overland, J. E., Wood, K. R., and Wang, M.: Warm Arctic - cold continents: climate impacts of the newly open Arctic sea, Polar Res., 30, 15787, doi:10.3402/polar.v30i0.15787, 2011.

Park, S. and Leovy, C. B.: Winter North Atlantic low cloud anomalies associated with the northern hemisphere annular mode, Geophys. Res. Lett., 27, 3357-3360, doi:10.1029/2000GL011609, 2000.

Perlwitz, J. and Graf, H.-F.: The statistical connection between tropospheric and stratospheric circulation of the Northern hemisphere in winter, J. Climate, 8, 2281-2295, 1995.

Previdi, M. and Veron, D. E.: North Atlantic cloud cover response to the North Atlantic oscillation and relationship to surface temperature changes, J. Geophys. Res., 112, D07104, doi:10.1029/2006JD007516, 2007.

Rigor, I. G., Wallace, J. M., and Colony, R. L.: Response of sea ice to the Arctic Oscillation, J. Climate, 15, 2648-2663, 2002.

Semenov, V. A., Latif, M., Jungclaus, J. H., and Park, W.: Is the observed NAO variability during the instrumental record unusual?, Geophys. Res. Lett., 35, L11701, doi:10.1029/2008GL033273, 2008.

Serreze, M. C. and Barry, R. G.: Synoptic Activity in the Arctic Basin, 1979-85, J. Climate, 1, 1276-1295, 1988.

Shupe, M. D., Walden, V. P., Eloranta, E., Uttal, T., Campbell, J. R., Starkweather, S. M., and Shiobara, M.: Clouds at Arctic atmospheric observatories, Part I: Occurrence and macrophysical properties, J. Appl. Meteor. Clim., 50, 626-644, 2011.

Stephens, G. L., Vane, D. G., Boain, R. J., Mace, G. G., Sassen, K., Wang, Z., Illingworth, A. J., O'Connor, E. J., Rossow, W. B., Durden, S. L., Miller, S. D., Austin, R. T., Benedetti, A., Mitrescu, C., and the CloudSat Science Team: The CloudSat Mission and the A-TRAIN: A new dimension to space-based observations of clouds and precipitation, B. Am. Meteorol. Soc., 83, 1771-1790, 2002.

Strong, C. and Magnusdottir, G.: Tropospheric Rossby Wave breaking and the NAO/NAM, J. Atmos. Sci, 65, 2861-2876, doi:10.1175/2008JAS2632.1, 2008.
Svensson, G. and Karlsson, J.: On the Arctic Wintertime Climate in Global Climate Models, J. Climate, 24, 5757-5771, doi:10.1175/2011JCLI4012.1, 2011.

Thompson, D. W. J. and Wallace, J. M.: The Arctic Oscillation signature in the wintertime geopotential height and temperature fields, Geophys. Res. Lett., 25, 1297-1300, 1998.

Thompson, D. W. J. and Wallace, J. M.: Annular Modes in the extratropical circulation. Part I: Month-to-month variability, J. Climate, 13, 1000-1016, 2000.

Thompson, D. W. J. and Wallace, J. M.: Regional climate impacts of the Northern, Hemisphere Annular Mode and associated climate trends, Science, 293, 85-89, 2001.

Thompson, D. W. J., Wallace, J. M., and Hegerl, G. C.: Annular modes in the extratropical circulation. Part II: Trends, J. Climate, 13, 1018-1036, 2000.

Tjernström, M., Sedlar, J., and Shupe, M. D.: How well do regional climate models reproduce radiation and clouds in the Arctic? An evaluation of ARCMIP simulations, J. Appl. Meteorol. Clim., 47, 2405-2422, 2008.

Trigo, R. M., Osborn, T. J., and Corte-Real, J. M.: The North Atlantic Oscillation influence on Europe: Climate impacts and associated physical mechanisms, Clim. Res., 20, 9-17, 2002.

Vavrus, S. J., Waliser, D., Schweiger, A., and Francis, J.: Simulations of 20th and 21st century Arctic cloud amount in the global climate models assessed in the IPCC AR4, Clim. Dynam., 33, 1099-1115, doi:10.1007/s00382-008-0475-6, 2008.

Wang, X. and Key, J. R.: Recent Trends in Arctic Surface, Cloud, and Radiation Properties from Space, Science, 299, 1725-1728, doi:10.1126/science.1078065, 2003.

Wang, X. and Key, J. R.: Arctic Surface, Cloud, and Radiation Properties Based on the AVHRR Polar Pathfinder Dataset. Part II: Recent Trends, J. Climate, 18, 2575-2593, 2005.

Winker, D. M., Vaughan, M. A., Omar, A. H., Hu, Y., Powell, K. A., Liu, Z., Hunt, W. H., and Young, S. A.: Overview of the CALIPSO Mission and CALIOP Data Processing Algorithms, J. Atmos. Ocean. Tech., 26, 2310-2323, doi:10.1175/2009JTECHA1281.1, 2009.

Woolings, T., Hoskins, B., Blackburn, M., and Berrisford, P.: A New Rossby Wave Breaking Interpretation of the North Atlantic Oscillation, J. Atmos. Sci., 65, 609-626, doi:10.1175/2007JAS2347.1, 2008. 